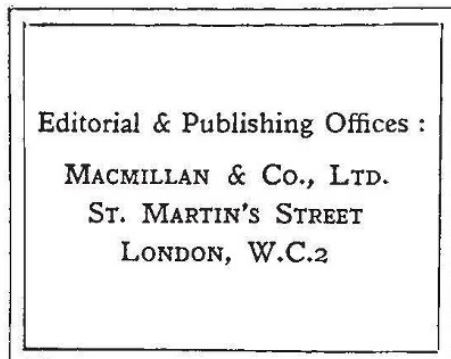

No. 3507

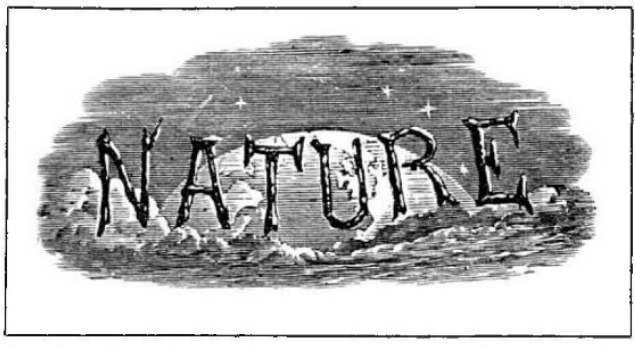

SATURDAY, JANUARY I6, I937
Telegraphic Address :

Phusis, LesQuARE, LONDON

Telephone Number :

WHITEHALL 883I

\title{
Human Problems of Progressive Industry
}

IN $\mathrm{N}$ discussing the impact of science upon society in his presidential address at Blackpool to the British Association, Sir Josiah Stamp referred to the necessity of more science to cure the evils which resulted from the impact of science. Ordered knowledge and principles are wanted at every point, and particularly the type of work carried out by the National Institute of Industrial Psychology. Some of its inquiries attempt to improve existing conditions of work. Other investigations endeavour to determine the conditions which allow greater output and efficiency, but much of the work of the Institute is directly designed to combat the evils arising from the new conditions created by modern demandsspeed, accuracy and intensity.

While the work of the National Institute of Industrial Psychology thus invokes the aid of many branches of science and is designed to assist in the adjustment of society to the changes caused by technical development, its support is left to personal advocacy. The financial resources of the Institute are only a fraction of the expenditure on research in a single industry, such as rayon, although the contribution of its work to human welfare is immeasurably greater. This absence of assured support to which Sir Josiah Stamp referred so pointedly greatly handicaps the Institute in the prosecution of many of its fundamental investigations. Even if particular industrial firms make use of the Institute's investigators to an increasing extent, industry and society as a whole cannot in this way reap anything like the potential assistance which the Institute could give in smoothing over the transition and readjustment of society under the impact of science.
The endowment of the National Institute of Industrial Psychology, to enable it to carry out its investigations on a scale commensurate with its potentialities in the field of social and industrial welfare, should prove a profitable investment from the point of view of industrial as well as social efficiency, and might well form one of the first objectives of scientific workers in the field of social science. Moreover, the potentialities of vocational guidance, in which field the Institute has carried out such admirable work, as a factor in avoiding misfits and checking juvenile unemployment, can scarcely be said as yet to have received anything like adequate appreciation, although the impending shortage of juvenile labour makes the work the more important.

The importance of research of this type was stressed by Sir Kenneth Lee in an address to the Bradford Textile Society on November 17. Sir Kenneth urged that research on the human side is just as important in modern industry as research on the chemical and physical properties of the products being manufactured. Discontent and unrest are often due largely to working conditions, and a central co-operative research association should give its attention to the investigation of problems of this type. Causes of workers leaving, abnormal labour turnover, absenteeism, or high sickness incidence demand as rigorous attention and investigation as a fall in the efficiency of a manufacturing process, and fatigue and incentives are fields which should amply repay any research carried out in them.

Like so many other speakers on this question, Sir Kenneth Lee once more emphasized the significance of management in industrial efficiency. 
The very rapidity of change and development in industry to-day tends to make plant and machinery of secondary importance. The greatest asset of a business is increasingly the ability of its staff. Significantly enough, this is essentially the first point emphasized in the report of an inquiry into vocational education after general education up to sixteen years of age carried out by a Committee on Commercial and Industrial Education of the British Association.

This Committee in its report emphasizes the growing tendency of firms to recruit university graduates, not for their technical knowledge but because of their disciplined mind and trained intelligence, for some of the higher administrative posts in business. Thus increasing use of the university graduate in technical capacities is likely to be paralleled in his employment in administrative capacities. Similarly the Committee notes the tendency of the larger firms to select an increasing proportion of boys from secondary and public schools at the age of eighteen years.

These factors alone indicate the way in which the standard of recruitment is being raised in industry. They also intensify the problem of vocational guidance, the use of which to prevent misfits either at the start or in selection for promotion to higher managerial posts becomes increasingly desirable and important. One of the arguments in favour of part-time education is, in fact, that entrance to employment at sixteen years of age results in fewer ultimate misfits than entry at eighteen years, when valuable time may have been spent in preparing for a particular occupation.

That more strenuous efforts should be made to eliminate or rather prevent misfits occurring in all ranks of industry is undoubtedly true, if we are to attain the standard of efficiency visualized both by Sir Josiah Stamp and Sir Kenneth Lee, and part-time education may be an important factor in that effort. The report makes it clear that the part-time education required to-day is not of the evening-class type upon which such reliance was formerly put and upon which severe comments have been made in recent years. It is part-time day education in which industry has arranged for the release of its young employees during working hours. Moreover, it is suggested that the sandwich type of vocational education, under which alternate periods of, for example, six months, are spent in the works and at school, should be adopted more frequently as a means of training suitable candidates for posts of higher responsibility.
This suggestion is, of course, essentially similar to the seconding of selected individuals of proved ability and sufficient experience for special training in management and administration with the view of recruiting them for the higher managerial posts as vacancies and opportunities occur. The recently announced staff college to be established near Derby by the London, Midland and Scottish Railway is essentially a development on these lines.

Such developments tend to diminish the importance of, and demand for, full-time vocational training for recruits for industry up to sixteen years of age, although at the same time the need for vocational guidance is enhanced and also the efficiency of vocational training after that age. The later age of entry to industry, whether from school or university, will increasingly be accompanied by a short intensive course of training after entering industry, designed to assist in the transition from school to work and in the application of the disciplined mind and scientific principles acquired in a liberal education to the particular problems characteristic of the branch of industry involved.

One important effect of the rising standard of management should undoubtedly be increasingly felt. The management of to-morrow will, as Sir Kenneth Lee suggests, attach increasing import. ance to the human factor. It will accordingly make much fuller use of methods of vocational selection and guidance, and may be expected to support much more generously and widely investigations on the long-range and practical problems involved, whether the research is initiated within a particular firm or by a research association or by such an organization as the National Institute of Industrial Psychology. Management of this type will not tolerate the position so strongly criticized by Sir Josiah Stamp, but it should not be necessary to wait for the rising standard of administration in industry to secure any important modification of the present anomalous position.

At the present time, apart from the National Institute of Industrial Psychology and the work of the Industrial Health Research Board, little attack is being made on the broader and more general problems akin to the long-range and fundamental work in the physical sciences which is at present so largely the domain of the universities. Even if the work done in the field of industrial relations in different universities were extended to cover the study of social change and 
the industrial surveys and studies of juvenile unemployment, of wage payments and labour conditions and of the location of British industry, which in recent years have been or are being carried out by the Economics Research Section of the Faculty of Commerce and Administration at the University of Manchester, for example, found parallels in the majority of our universities, still the consulting work of the National Institute of Industrial Psychology would be required on a much wider scale.

There are in fact two main needs. The first is a growing appreciation of the importance of the social and human factors, which would naturally be accompanied by a greater realization of the value of the Institute's work and a greater willingness to support it freely. In meeting this need the more effective training for management will assist, but scientific workers can equally play their part by following Sir Lenneth Kee's example. The second need is that of planning the resources available both within industry and without, so as to secure that a concerted attack is made on the problems confronting us and that the knowledge acquired is made available as widely as possible for immediate application. This again can only be completely met as industrial leadership becomes conscious of its opportunities and responsibilities, but even to-day much more could be done to create or arouse interest, above all if scientific workers set themselves seriously to formulate a plan and to outline the agencies and means and resources for its execution. The demonstration of the way in which bad social or industrial systems or conditions frustrate science and lower industrial or social efficiency, or the factors which tend to diminish such efficiency is, as Mr. J. G. Crowther has reminded us, one of the major social responsibilities of scientific workers, and one which their position in industry to-day gives them increasing opportunities to discharge.

At the same time, many of the fundamental factors involved must be ascertained by the academic worker. Dr. Julian Huxley has pointed out the necessity for creating research institutes where work of the independent type carried out in a university is possible. A true social service can only evolve when such problems as unem. ployment are studied over the whole range of society, and the opportunities which already exist in Government service in regard to planning and social and industrial surveys as well as in industry, both in regard to economics, labour and welfare questions and the study of public relations, are supplemented in this way.

Apart altogether from the need for more experiments of the regional type exemplified by that which has been put into force under the Tennessee Valley Authority Law of May 18, 1933, social service has yet to formulate its methods. Progress is delayed by the absence of an adequate technique as much as by anything else. Particularly is this true when multiple causation and multiple effect complicate almost every social problem, and the investigation has to take account of several contributory factors or causes and as many or more effects. The practical impossibility of achieving complete isolation demands an appropriate technique in handling such ideas in scientific practice.

Nor are these the only difficulties to which Dr. Huxley has directed attention. The loose discussion of abstract terms, such as justice and truth, is a stumbling block, and such terms require rigid exclusion from sociological discussions. Here scientific workers could do much more to organize the concerted exposure of those who by jargon and misleading or inaccurate phraseology persistently oppose progress. Again, the social investigator cannot ignore prejudices. He has to learn to discount and control bias and to study the whole question of the place and use of propaganda and enthusiasm.

The fundamental reason for the wider interest in applications of science to social questions to day, whether in the industrial world or not, as for the development of a true science of society, is the belief that the accumulation of social knowledge along scientific lines provides a basis for better and more effective social action. We can scarcely contemplate any branch of applied science to-day, or any of the new powers, such as broadcasting, with which it has endowed mankind, without realizing the tremendous possibilities for good or for evil which turn on the use or abuse of that knowledge and those powers. If the increasing direction of industry by science initiates much more research into the human problems of industry, that is likely to be but one step more towards the conversion of science from a series of isolated social nerve centres into that which Dr. Huxley firmly maintains it is intended to be--a real brain for society. Not the least consequence of such a transformation would be the development of social mechanisms designed to prevent the appalling blots in our present social system represented by the "Special Areas" of Great Britain. 